Phonon Densities of States and Related Thermodynamic

Properties of High Temperature Ceramics*

\author{
C.-K. Loong ${ }^{1}$ \\ Intense Pulsed Neutron Source Division \\ Argonne National Laboratory, Argonne IL 60439 U. S. A.
}

To be presented at the Conference on
New Developments in High Temperature Ceramics
Istanbul, Turkey
August 12-15, 1998

To be published in the Journal of European Ceramic Society

*An invited paper

'E-mail: ckloong@anl.gov 


\section{DISCLAIMER}

This report was prepared as an account of work sponsored by an agency of the United States Government. Neither the United States Government nor any agency thereof, nor any of their employees, make any warranty, express or implied, or assumes any legal liability or responsibility for the accuracy, completeness, or usefulness of any information, apparatus, product, or process disclosed, or represents that its use would not infringe privately owned rights. Reference herein to any specific commercial product, process, or service by trade name, trademark, manufacturer, or otherwise does not necessarily constitute or imply its endorsement, recommendation, or favoring by the United States Government or any agency thereof. The views and opinions of authors expressed herein do not necessarily state or reflect those of the United States Government or any agency thereof. 


\section{DISCLAIMER}

Portions of this document may be illegible in electronic image products. Images are produced from the best available original document. 


\title{
Phonon Densities of States and Related Thermodynamic Properties \\ of High Temperature Ceramics
}

\author{
C.-K. Loong* \\ Intense Pulsed Neutron Source Division \\ Argonne National Laboratory, Argonne IL 60439 U. S. A.
}

\begin{abstract}
Structural components and semiconductor devices based on silicon nitride, aluminum nitride and gallium nitride are expected to function more reliably at elevated temperatures and at higher levels of performance because of the strong atomic bonding in these materials. The degree of covalency, lattice specific heat, and thermal conductivity are important design factors for the realization of advanced applications. We have determined the phonon densities of states of these ceramics by the method of neutron scattering. The results provide a microscopic interpretation of the mechanical and thermal properties. Moreover, experimental data of the static structures and dynamic excitations of atoms are essential to the validation of interparticle potentials employed for molecular-dynamics simulations of high-temperature properties of multicomponent ceramic systems. We present an overview of neutron-scattering investigations of the atomic organization, phonon excitations, as well as calculations of related thermodynamic properties of $\mathrm{Si}_{3} \mathrm{~N}_{4}, \beta$-sialon, AlN and GaN. The results are compared with those of the oxide analogs such as $\mathrm{SiO}_{2}$ and $\mathrm{Al}_{2} \mathrm{O}_{3}$.
\end{abstract}

Running title: Phonon Densities of States and Thermal Properties of High Temperature Ceramics

\footnotetext{
·E-mail: ckloong@anl.gov
}

The submitted manuscript has been created by the University of Chicago as Operator of Argonne National Laboratory ("Argonne") under Contract No. W-31-109-ENG-38 with the U.S. Department of Energy. The U.S. Government retains for itself, and others acting on its behalf, a paid-up, nonexclusive. irrevocable worldwide license in said article to reproduce, prepare derivative works, distribute copies to the public, and perform pub. licly and display publicly, by or on behalf of the Government. 
1. Introduction

Advanced materials with tailored properties suitable for applications in extreme environments are in great demand. One of the important goals in materials design is to be able to introduce specific desirable properties into certain components of a complex system at an early stage during fabrication and to predict the performance of the final product. One approach toward this goal is to establish a database of atomic-level structures and dynamic response of a variety of key materials and sophisticated algorithms for large-scale computations. On the experimental side, slow (cold to epithermal) neutrons probe directly the organization and dynamic response of atomic nuclei and electrons in a substance (bulk and low-dimensional) thereby providing a valuable means for a microscopic interpretation of materials properties.

Presently, neutron diffraction is widely used to probe the atomic and spin organization. Multiple phrasal analyses of crystal structures are now routinely applied. Partial structure factors of atom-atom correlations in liquids and amorphous materials can be obtained from measurements of specimens with selective isotopic substitution. The penetration power of neutrons in most materials provides the opportunity of surveying the interior of large $(\sim \mathrm{cm})$ samples. As the resolution of the diffractometers improves, various intrinsic properties such as crystalline or magnetic domain size, microstrains, defects or faults, and residual strains can be measured: Small-angle scattering enables the measurements of microstructure such as pore/particle distribution over a matrix, phase separated precipitates (and the magnetic analogs) of size up to about $500 \mathrm{~nm}$. Larger-scale structures up to $\mu \mathrm{m}$ in ceramics can be investigated from the analysis of the multiple-scattering profiles. The atomic or magnetization density variation and mass transport across an interface can be studied by neutron reflectometry. Atomic vibrations (phonons) are the principal excitations responsible for the thermodynamic behavior of 
insulating or semiconducting ceramics. Quasielastic and inelastic scattering obtained from neutron spectroscopy permit a direct measurement of the underlying atomistic or spin dynamics.

Detailed information regarding the atomic motion (phonon) in a crystalline system can be obtained through joint analysis of the measured dynamic structure factors, $S(Q, E)$ where $\mathbf{Q}$ and $\mathrm{E}$ are the neutron wavevector and energy transfer, respectively, and molecular-dynamics (MD) simulations or lattice-dynamics (LD) modeling. Although phonons can be investigated using several experimental techniques including Raman, infrared and neutron spectroscopy. Only neutrons can probe phonon modes throughout the Brillouin zone, and the method is not restricted by selection rules and is relatively insensitive to small amount of impurities. In this paper we present the recent studies of phonons of the $\mathrm{SiO}_{2}-\mathrm{Si}_{3} \mathrm{~N}_{4}-\mathrm{AlN}-\mathrm{Al}_{2} \mathrm{O}_{3}$ system and point out the connections between the neutron data and the thermal properties. A scheme of combining neutron experiments and large-scale $\mathrm{MD}$ simulations towards to goal of designing hightemperature ceramics is discussed.

2. Phonons in the $\mathrm{SiO}_{2}-\mathrm{Si}_{3} \mathrm{~N}_{4}-\mathrm{AlN}-\mathrm{Al}_{2} \mathrm{O}_{3}$ system

Fig. 1 shows the phase diagram of the $\mathrm{SiO}_{2}-\mathrm{Si}_{3} \mathrm{~N}_{4}-\mathrm{AlN}-\mathrm{Al}_{2} \mathrm{O}_{3}$ system which encompasses many of the most promising ceramics for high-temperature applications. ${ }^{1} \mathrm{~A}$ rigorous and systematic study of the end compounds, silica, silicon nitride, aluminum nitride and alumina, will pave the way for further development of new ceramic alloys and composites possessing superior properties. An understanding of the atomic dynamics within these monolithic compounds is an important prerequisite. The first phase involves measurements of the phonon densities of states (PDOS) by neutron spectroscopy and data analyses by MD simulations or LD model calculations. The next phase includes large-scale computer simulations of alloys or composites using the atomic potentials developed for interactions within individual 
components as well as across different components, and further comparison with experiments. In the following we shall discuss mainly the PDOS measurements and data interpretation. The neutron inelastic experiments were performed using a time-of-flight chopper spectrometer, HRMECS, at the Intense Pulsed Neutron Source (IPNS) of Argonne National Laboratory. Details of the spectrometer and experimental procedure were given elsewhere..$^{2,3}$

2a. Silica

Silica is one of the most widely used and studied ceramics. Fig. 2 shows the generalized PDOS of vitreous silica at $10 \mathrm{~K}$ obtained from a neutron measurement. It differs from the true PDOS in the weighting of the density over the phonon energy, namely, the generalized PDOS is a sum of the partial PDOS of the constituent atoms weighted by their neutron scattering density and the inverse of their masses. The sharp peaks around 50,100,130-150 meV can loosely interpreted as arising from the rocking, symmetric stretch and asymmetric stretch of the $\mathrm{O}$ atoms relative to the Si neighbors. ${ }^{4-7}$ The broad features reflect the wide distribution of the $\mathrm{Si}-\mathrm{O}-\mathrm{Si}$ bond angles within the 3-D network of corner-sharing of $\mathrm{SiO}_{4}$ tetrahedral units, the varyingly mixed bending and stretching character, and contribution from Si motion. ${ }^{8}$ The origin of the splitting in the $130-160 \mathrm{meV}$ region is still a subject of debate. ${ }^{9}$ From the viewpoint of mechanical strength, vitreous silica or quartz has relatively low bulk modulus and hardness due to the weakness against the titling of the $\mathrm{SiO}_{4}$ tetrahedra. However, the high-pressure phase of silica, stishovite, which consists of a more compact packing of $\mathrm{SiO}_{6}$ octrahedra, has a substantially higher hardness. ${ }^{10}$ To date there is no experimental data on the PDOS of stishovite, or MD simulation that is capable to explain the formation or structure of the various polymorphs of silica.

2b. Silicon nitride 
Silicon nitride has been at the forefront of research for high-temperature, high-strength materials. The combination of low thermal expansion and high strength results in superb thermal-shock resistance, and the strong covalent bonding between the atoms gives rise to high resistance to mechanical deformation and chemical corrosion. The PDOS of a $\beta-\mathrm{Si}_{3} \mathrm{~N}_{4}$ powder obtained from neutron-scattering measurements is shown in Fig. 3. The crystal structure (space group $P \sigma_{3} / m$, two formula units/unit cell) consists of slightly distorted, corner-sharing $\mathrm{SiN}_{4}$ tetrahedra chains parallel to the crystallographic c-axis. ${ }^{11}$ Parallel to the hexagonal basal plane $\mathrm{Si}-\mathrm{N}$ atomic layers are stacked in alternating sequence, $\mathrm{ABABAB} \ldots$ Each $\mathrm{N}$ atom on a $2 \mathrm{c}$ site is coordinated by three $\mathrm{Si}$ atoms in a mirror plane. One of the $\mathrm{Si}-\mathrm{N}$ bonds of this triangular unit connects two adjacent $\mathrm{SiN}_{4}$ chains running parallel to the c-axis. However, unlike the crystal structure of a related compound of $\mathrm{Si}_{2} \mathrm{~N}_{2} \mathrm{O}$ (orthorhombic, $\mathrm{Cmc2}$ ), the crystal structure does not allow cooperative reorientation of the tetrahedra through either static atomic displacements or lattice vibrations. This factor was attributed to the superiority of high-pressure behavior of $\beta$ $\mathrm{Si}_{3} \mathrm{~N}_{4}$ to $\mathrm{Si}_{2} \mathrm{~N}_{2} \mathrm{O} .12$

The generalized PDOS of $\beta-\mathrm{Si}_{3} \mathrm{~N}_{4}$ displays two bands, a broad one centered around 50 $\mathrm{meV}$ and a sharp one at about $115 \mathrm{meV}$. The low-energy region (below $40 \mathrm{meV}$ ) involves mainly the lattice vibrations of the tetrahedra network. The 50 and $115 \mathrm{meV}$ bands may be assigned to the bending and stretching of the $\mathrm{Si}-\mathrm{N}$ bonds, respectively. The relatively narrow peaks reflect a rather uniform distribution of force fields for the local vibrations of $\mathrm{Si}$ and $\mathrm{N}$ atoms. The solid line in Fig. 3 corresponds to the MD simulations of the generalized PDOS which is in fairly good agreement with the experimental data. The MD simulations also reproduced correctly the bulk modulus and lattice specific heat over the $300-1700 \mathrm{~K}$ temperature range. ${ }^{13}$

2c. Aluminum nitride and gallium nitride 
Aluminum nitride is an electronic ceramic which exhibits high electrical resistivity, good dielectric strength, a thermal expansion coefficient closely matching that of silicon, non-toxicity and outstanding thermal conductivity. These properties make AlN ideal for microelectronic substrate applications. Furthermore, densified AIN has high strength, high thermal stability and corrosion resistance. Therefore, it can potentially be used under extreme conditions. AIN crystallizes in the hexagonal wurtzite structure in which each atom is coordinated by four nearest neighbors forming a tetrahedron. Fig. 4 shows the generalized PDOS of AlN determined by neutron spectroscopy using a polycrystalline sample. A rigid-ion model was applied to the interpretation of the data. After optimization, the model provided a satisfactory description of the neutron results as well as the Raman and IR data,sound-velocity measurements and the lattice specific heat. 14

The calculated phonon dispersion curves along the major symmetry directions of the reduced Brillouin zone according to the optimized rigid-ion model are plotted in Fig. 5 together with the true DOS. The two sharp bands at about 85 and $92 \mathrm{meV}$ arise from the 6 uppermost optic modes which exhibit little dispersion. A narrow gap separates these flat modes from the lower, more dispersive branches. The broad peak centered at $\sim 35 \mathrm{meV}$ contains many unresolved critical frequencies at the zone center and boundaries (van Hove singularities). Below $\sim 30 \mathrm{meV}$ the DOS exhibits the Debye-like $\sim \mathrm{E}^{2}$ dependence. The steep longitudinal and transverse acoustic branches, and the high phonon cut-off frequency are consistent with the high hardness and mechanical strength of the material.

It is of interest to compare the phonon spectrum of AlN with other binary wurtzite nitrides, particularly gallium nitride. GaN is the basic ingredient of a new class of highbrightness blue and green light-emitting devices. Semiconductor devices based on GaN, e. g., light-emitting diodes and diode lasers are expected to function more reliably, at higher powder 
and frequencies, and at elevated temperatures because of the stronger atomic bonding in the IIIV nitrides as compared to the II-IV analogs. In Fig. 6 we compare the true PDOS of GaN and AIN. ${ }^{15}$ Firstly, the Debye-like $\sim E^{2}$ behavior extends to a higher energy $(\sim 30 \mathrm{meV})$ in AlN than in GaN ( $20 \mathrm{meV})$. Phonons in this region are important to the low-temperature thermal conductivity. The more extensive Debye-like region of AIN implies a higher thermal conductivity of AIN at low temperatures. ${ }^{16,17}$ Secondly, AIN exhibits a somewhat higher onephonon cut-off energy. The splitting of the two high-energy optic bands in GaN is more pronounced. This energy separation originates in part from the macroscopic electric fields generated by the net ionic charges which splits the LO-like and TO-like phonons. ${ }^{18}$ Therefore, $\mathrm{GaN}$ is more ionic than AlN, as also suggested by electronic band calculations. ${ }^{19}$ Thirdly, $\Theta_{\mathrm{D}}(0 \mathrm{~K})$ is larger for AlN $(800 \mathrm{~K})$ than for $\mathrm{GaN}(560 \mathrm{~K})$. These facts imply a higher microhardness of AlN than GaN. ${ }^{20}$

\section{2d. Alumina}

Transitions of various crystalline phases of alumina occur over a wide range of . temperatures $\left(-300-1200^{\circ} \mathrm{C}\right)$. Depending on the chemical routes in synthesis, heat-treatment temperatures, atmospheric conditions and other factors, these intermediate phases, collectively referred to as transition aluminas, often coexist metastably in a gel or powder. ${ }^{21}$ The crystal structure of aluminum hydroxide, the precursor of low-temperature phases of transition alumina, is based on close-packing of hydroxyl ions in planar sequence of $\mathrm{ABAB}$..., with $\mathrm{Al}$ ions filling up to two-thirds of the octahedral interstitial sites. During heating at temperatures between $900-$ $1400 \mathrm{~K}$, progressive dehydration and desorption of surface hydroxyl groups lead to the formation of various phases of transition aluminas. A portion of the $\mathrm{Al}$ ions changes their local coordination with $O$ from octahedral symmetry in the hydroxide structure to tetrahedral 
interstices. Above about $1400 \mathrm{~K}$ formation of the $\alpha-\mathrm{Al}_{2} \mathrm{O}_{3}$ (corundum)occurs rapidly, and the $\mathrm{Al}$ ions return to octahedral symmetry governed by the trigonal structure (space group $R \overline{3 c}$ ). ${ }^{22}$

Porous transition aluminas are widely used as catalytic supports for noble metals in various chemical processes and automobile-emission control. The high melting point, excellent electrical resistivity and high hardness of corundum make it attractive for applications ranging from wear-resistant and electrically insulating components to biomedical implants. The generalized PDOS of corundum is shown in Fig. 7. It displays multiple, overlapping bands extending to about $110 \mathrm{meV}$. The high-energy modes above $60 \mathrm{meV}$ are mostly due to vibrations of $\mathrm{O}$ atoms. The solid line represents the calculated generalized PDOS obtained from MD simulations based on the ES+ potential model. The low-energy $(<60 \mathrm{meV})$ excitations and the band around $95 \mathrm{meV}$ agree well with $\mathrm{MD}$ result. However, the experimental plateau-like structure between 60 and $90 \mathrm{meV}$ is not present in the $\mathrm{MD}$ generalized PDOS.

.2e. $\mathrm{Si}_{6-\mathrm{z}} \mathrm{Al}_{\mathrm{z}} \mathrm{O}_{\mathrm{z}} \mathrm{N}_{8-\mathrm{z}}(0 \leq \mathrm{z} \leq 6)$ including $\beta$-Sialon

Sialon ceramics as structural materials are usually densified by hot pressing or hot isostatic pressing methods. Recently, reaction-sintered $\beta$-sialon ceramics, $\mathrm{Si}_{6-\mathrm{z}} \mathrm{Al}_{\mathrm{z}} \mathrm{O}_{\mathrm{z}} \mathrm{N}_{8-\mathrm{z}}(0 \leq \mathrm{z}$ $\leq 4)$, have been fabricated using aqueous slurries by a slip-casting technique. ${ }^{23}$ Such a technique has an obvious advantage, namely, the capability of forming relatively complex shapes by using inexpensive plaster molds. The fabrication process, mechanical properties, and crystal structures of these slip-cast materials, $\mathrm{Si}_{6-z} \mathrm{Al}_{z} \mathrm{O}_{z} \mathrm{~N}_{8-z}(0 \leq z \leq 6)$, have been given elsewhere.23, 24

$\beta$-sialon, described by the formula $\mathrm{Si}_{6-z} \mathrm{Al}_{z} \mathrm{O}_{z} \mathrm{~N}_{8-\mathrm{z}}(0 \leq z \leq 4)$, are formed from a solid solution extended along a constant metal-to-nonmetal atomic ration, $(\mathrm{Si}, \mathrm{Al}):(\mathrm{O}, \mathrm{N})$, see Fig. 1. It has a nominal crystal structure identical to that of $\beta-\mathrm{Si}_{3} \mathrm{~N}_{4}$, although a consistent preferential 
occupation of the $2 \mathrm{c}$ sites by $\mathrm{O}$ atoms and the $6 \mathrm{~h}$ sites by $\mathrm{N}$ atoms prevail over the entire composition. ${ }^{3}$ Fig. 8 shows the observed generalized PDOS of selective $\mathrm{Si}_{6-z} \mathrm{Al}_{z} \mathrm{O}_{2} \mathrm{~N}_{8-z}(0 \leq z \leq$ 6) ceramics and a pure $\beta-\mathrm{Si}_{3} \mathrm{~N}_{4}$ powder. The spectra of $\beta$-sialon $(0 \leq z \leq 4)$ show a one-phonon DOS extending to $\sim 170 \mathrm{meV}$ with two broad bands centered at about 50 and $115 \mathrm{meV}$. The lowenergy region $(<40 \mathrm{meV})$ involves mainly the lattice vibrations of the tetrahedra network. The $50-\mathrm{meV}$ and $115-\mathrm{meV}$ bands may be assigned to bending and stretching of the $\mathrm{Si}(\mathrm{Al})-\mathrm{N}(\mathrm{O})$ bonds, respectively. The DOS of the $z=0$ ceramic resembles closely that of the $\mathrm{Si}_{3} \mathrm{~N}_{4}$ powder excepting the somewhat sharper features in the powder sample. This probably reflects a larger strain distribution over the crystalline grains in the ceramic sample resulted from the sintering process. As Si and $\mathrm{N}$ are replaced by $\mathrm{Al}$ and $\mathrm{O}$ in the $\mathrm{z} \geq 1$ samples, the two vibrational bands broaden and the phonon densities in the $60-90 \mathrm{meV}$ and $130-150 \mathrm{meV}$ regions increase progressively. A slight increase of density below $\sim 30 \mathrm{meV}$ as increasing $z$ can also be seen: Thus the atomic dynamics shows a distinct response to the bonding environment due to chemical disorder over a wide range of vibrational frequencies.

$\mathrm{Si} 6-\mathrm{Zl}_{\mathrm{Z}} \mathrm{O}_{\mathrm{Z}} \mathrm{N} 8-\mathrm{Z}$ does not form single-phase materials for $\mathrm{z}>4$. Instead, complex, multiple crystalline phases were observed. Only a minute portion $(\sim 6 \%)$ of $\beta$-sialon phase remains in $\mathrm{SiAl}_{5} \mathrm{O}_{5} \mathrm{~N}_{3}$. The predominant phase in the $\mathrm{z}=5$ sample is $\alpha-\mathrm{Al}_{2} \mathrm{O}_{3}$. The predominant phase in the $\mathrm{z}=6$ sample was identified as the cubic phase $\mathrm{Al}_{3} \mathrm{O}_{3} \mathrm{~N}$ having the same structure as $\mathrm{Al}_{2} \mathrm{MgO}_{4}$. This explains the drastic difference between the PDOS of the $z \leq 4$ and the $z=5-6$ materials. In fact, the PDOS of the $z=6$ sample resembles a superposition of the PDOS of $\alpha-\mathrm{Al}_{2} \mathrm{O}_{3}$ and $\mathrm{AIN}$. Given the existence of data on the crystal structures, phonons, and mechanical properties of $\mathrm{Si}_{6-\mathrm{z}} \mathrm{Al}_{\mathrm{z}} \mathrm{O}_{z} \mathrm{~N}_{8-\mathrm{z}}(0 \leq z \leq 6)$ ceramics, it is of interest to extend the MD simulations of $\mathrm{Si}_{3} \mathrm{~N}_{4}$ to this system and calculate the high-temperature properties. 
3. Future direction: computer-aided materials design

The accumulative experience from experimental and MD investigations of the parent ceramics in the $\mathrm{SiO}_{2}-\mathrm{Si}_{3} \mathrm{~N}_{4}-\mathrm{AIN}-\mathrm{Al}_{2} \mathrm{O}_{3}$ system is valuable for further studies of the ceramic alloys which contains a variety of new phases. Some of them may represent new ceramics offering combined merits of their parent materials. Currently, knowledge regarding the atomic structures and thermophysical behavior of these solution phases is far from complete. In the $\mathrm{SiO}_{2}$-rich region of the phase diagram, the readiness of forming liquid and glassy phases at lower temperatures facilitates the binding of $\mathrm{Si}_{3} \mathrm{~N}_{4}$-based crystalline grains to form dense green bodies. However, the presence of intergranular glass residues is known to degrade the modulus of rupture at high temperatures. The $\mathrm{X}$-phase of approximate composition of $\mathrm{Si}_{3} \mathrm{Al}_{6} \mathrm{O}_{12} \mathrm{~N}_{2}$ formed near the liquid-phase region has not been well characterized. It is of interest to compare the PDOS of $\mathrm{O}^{\prime}$-sialon, $\mathrm{Si}_{2-\mathrm{x}} \mathrm{Al}_{\mathrm{x}} \mathrm{O}_{1+\mathrm{x}} \mathrm{N}_{2-\mathrm{x}}(0<\mathrm{x}<0.2)$, which is isostructural to $\mathrm{Si}_{2} \mathrm{~N}_{2} \mathrm{O}$, with those - of $\mathrm{Si}_{3} \mathrm{~N}_{4}$ and $\beta$-sialons. Other crystalline phases of $\mathrm{AlONs}$ including $\mathrm{Al}_{3} \mathrm{O}_{3} \mathrm{~N}$ and a number of polytypoid phases related to the wurtzite-type structure of AIN have not been fully explored by neutron and $\mathrm{MD}$ studies.

The neutron PDOS is essential to the validation of the interatomic potentials employed by MD simulations. The additional dimension of phonon energies imposes a stringent condition for the compliance of the MD results with important thermodynamic quantities such as the free energy, entropy and specific heat. Once the reliability of the interparticle potentials for the key substances is verified by comparing with the static structure, atomic dynamics, and other macroscopic thermal and mechanical behavior, new composite materials with tailored properties may be "fabricated" by computer-aided simulations. ${ }^{25}$ For example, following the confirmation the structural and dynamics of crystalline and amorphous $\mathrm{Si}_{3} \mathrm{~N}_{4}$ with neutron results as well as 
elastic and thermodynamic data, Kalia, Vashishta and co-workers have extended the MD studies to sintering and fracture dynamics of $\mathrm{Si}_{3} \mathrm{~N}_{4}$ ceramics by large-scale simulations with parallel computers. ${ }^{26-28}$ Recently, the oxidation dynamics of nanophase aluminum clusters was investigated by MD simulations. ${ }^{29}$ This in turn gives rise to new predictions of materials properties to be examined experimentally.

Another area in the development of high-temperature ceramics is based on composite materials which may combine the strength and merits of various reinforcing components. The capability of computer assisted design of composites based on data of the individual components and knowledge of the interfaces is very important, otherwise designers are confronted with a vast range of compositions over which the properties cannot be optimized solely based on chemical insights in the starting materials. For example, a two-phase composite consisting of rare-earth orthophosphates $\left(\mathrm{RPO}_{4}, \mathrm{R}=\right.$ rare earths) and alumina were found to be machinable, and alumina fibers coated with rare-earth phosphates were superior to bare fibers in the prevention of fiber puncture. ${ }^{30}$ These phenomena are thought to be related to the relatively weak interfaces between alumina and phosphates. We have measured the phonon dispersion curves along major symmetry directions and the PDOS of $\mathrm{LuPO}_{4}$ by neutron scattering using single crystals and powder samples. ${ }^{31}$ The phonon data were analyzed by a LD shell model. An atomistic simulation of the $\mathrm{RPO}_{4}-\mathrm{Al}_{2} \mathrm{O}_{3}$ composites can, in principle, be carried out using the structural and dynamic information of alumina and $\mathrm{LuPO}_{4}$ based on the neutron data and an adjustable interfacial interaction scheme. Because of the high melting points $\left(-2000^{\circ} \mathrm{C}\right.$ for $\mathrm{RPO}_{4}$ and $2051^{\circ} \mathrm{C}$ for $\left.\alpha-\mathrm{Al}_{2} \mathrm{O}_{3}\right)$ and the chemical inertness, this ceramic composite system is expected to exhibit many attractive properties at high temperatures.

4. Summary 
The characterization of fundamental microscopic properties such as the crystal structures and PDOS by neutron-scattering experiments is valuable to large-scale molecular dynamics simulations of realistic materials properties. The joint neutron and MD study of $\mathrm{Si}_{3} \mathrm{~N}_{4}$ ceramic is an important step for the eventual prediction of high-temperature behavior. We have presented the phonon results from neutron measurements of important monolithic ceramics $\mathrm{SiO}_{2}$,

$\mathrm{Si}_{3} \mathrm{~N}_{4}, \mathrm{AIN}, \mathrm{GaN}$, and $\alpha-\mathrm{Al}_{2} \mathrm{O}_{3}$ as well as ceramic alloys of $\mathrm{Si}_{6-\mathrm{z}} \mathrm{Al}_{\mathrm{z}} \mathrm{O}_{\mathrm{z}} \mathrm{N}_{8-\mathrm{z}}(0 \leq \mathrm{z} \leq 6)$. These data are useful for further computer simulations of high-temperature properties of $\beta$-sialon and $\mathrm{RPO}_{4}-\mathrm{Al}_{2} \mathrm{O}_{3}$ composites.

\section{Acknowledgment}

I am indebted to many collaborators: T. J. Campbell, I. Ebbsjö, R. K. Kalia, A. Nakano, J. C. Nipko, S. Ogata, M. Ozawa, and S. Suzuki, K. Tsuruta, and P. Vashishta with whom I have enjoyed working in the course of these studies. Work performed at Argonne National -Laboratory is supported by the U. S. DOE-BES under Contract No. W31-109-ENG-38. 
References

1. Jack, K. H., Sialons and related nitrogen ceramics, J. Mat. Sci. 11, 1135 (1976).

2. Loong, C.-K., Ikeda, S., and Carpenter, J. M., The resolution function of a pulsed-source neutron chopper spectrometer, Nuclear Instruments and Methods in Physics Research A260, 381 (1987).

3. Loong, C.-K., Richardson, J. W., Jr., Suzuki, S., and Ozawa, M., Crystal phase and phonon densities of states of $\beta^{\prime}$-sialon ceramics $\mathrm{Si}_{6-\mathrm{z}} \mathrm{Al}_{\mathrm{z}} \mathrm{O}_{\mathrm{z}} \mathrm{N}_{8-\mathrm{z}}(0 \leq \mathrm{z} \leq 4)$ prepared by a slip-casting method, J. Am. Ceram. Soc. 79, 3250 (1996).

4. Bell, R. J., Bird, N. F., and Dean, P., J. Phys. C1, 299 (1968).

5. Bell, R. J., Dean, P., and Hibbins-Butler, D. C., J. Phys. C4, 1214 (1971).

6. Galeener, F. L., Leadbeeter, A. J., and Stringdellow, M. W., Phys. Rev. B27, 1052 (1983).

.7. Sen, P. N. and Thorpe, M. F., Phys. Rev. B15, 4030 (1977).

8. Arai, M., A, C. H., Otomo, T., Hiramatsu, A., and Nishijima, T., Dynamic correlation function studies of the medium-range order in materials, J. Non-Cryst. Solids 192\&193, 230 (1995).

9. Price, D. L. and Carpenter, J. M., Scattering function of vitreous silica, J. Non-Cryst. Solids 92, 153 (1987).

10. Léger, J.-M. and Haines, J., The search for superhard materials, Endeavour 21, 121 (1997).

11. Grün, R., The crystal stucture of $\beta-\mathrm{Si}_{3} \mathrm{~N}_{4}$ : structural and stability considerations between $\alpha-$ and $\beta-\mathrm{Si}_{3} \mathrm{~N}_{4}$, Acta Cryst. B 35, 800 (1979).

12. Cartz, L. and Jorgensen, J. D., The high-pressure behavior of $\alpha$-quartz, oxynitride, and nitride structures, J. Appl. Phys. 52, 236 (1981). 
13. Loong, C.-K., Vashishta, P., Kalia, R. K., and Ebbsjö, I., Crystal structure and phonon density of states of high-temperature ceramic silicon nitride, Europhys. Lett. 31, 201 (1995).

14. Nipko, J. C. and Loong, C.-K., Phonon excitations and related thermal properties of aluminum nitride, Phys. Rev. B 57, 10550 (1998).

15. Nipko, J. C.; Loong, C.-K., Balkas, C. M., and Davis, R. F., Phonon density of states of bulk gallium nitride, Appl. Phys. Lett. 73, 34 (1998).

16. Slack, G. A., A.Tanzilli, R., Pohl, R. O., and Vandersande, J. W., The intrinsic thermal conductivity of AIN, J. Phys. Chem. Solids 48, 641 (1987).

17. Sichel, E. K. and Pankove, J. I., Thermal conductivity of GaN, 25-360 K, J. Phys. Chem. Solids 38, 330 (1977).

18. Arguello, C. A., Rousseau, D. L., and Porto, S. P. S., First-order Raman effect in wurtzite-type crystals, Phys. Rev. 181, 1351 (1969).

19. Harrison, W. A. and Ciraci, S., Bond-orbital model. II, Phys. Rev. B 10, 1516 (1974).

20. Drory, M. D., Mechanical properties of gallium nitride and related materials, Mat. Res. Soc. Symp. Proc. 468, 201 (1997).

21. Lippens, B. C. and Boer, J. H. d., Study of phase transformation during calcination of aluminum hydroxides by selected area electron diffraction, Acta Cryst. 17, 1312 (1964).

22. Loong, C.-K., Richardson, J. W., Jr., and Ozawa, M., Structural phase transformations of rareearth modified transition alumina to corundum, J. Alloys Compounds 250, 356 (1997).

23. Suzuki, S., Nasu, T., Hayama, S., and Ozawa, M., Mechanical and thermal properties of $\beta^{\prime}-$ SiAlON prepared by a slip casting method, J. Am. Ceram. Soc. 79, 1685 (1996). 
24. Loong, C.-K., Richardson, J. W. J., Suzuki, S., and Ozawa, M., Crystal phases and lattice dynamics of slip-cast $\beta$ '-SiAlONs, Mat. Res. Soc. Symp. Proc. 410, 241 (1996).

25. Loong, C.-K., in Computer Aided Design of High Temperature Materials, edited by A. Pechenik, R. K. Kalia and P. Vashishta (Oxford University Press, Santa Fe, NM, 1998), p. In press.

26. Kalia, R. K., Nakano, A., Tsuruta, K., and Vashishta, P., Morphology of pores and interfaces and mechanical behavior of nanocluster-assembled silicon nitride ceramic, Phys. Rev. Lett. 78, 689 (1997).

27. Vashishta, P., Kalia, R. K., and Ebbsjö, I., Low-energy floppy modes in high-temperature ceramics, Phys. Rev. Lett. 75, 858 (1995).

28. Nakano, A., Kalia, R. K., and Vashishta, P., Dynamics and morphology of brittle cracks: a molecular-dynamics study of silicon nitride, Phys. Rev. Lett. 75, 3138 (1995).

29. Ogata, S., Campbell, T. J., Tsuruta, K., Nakano, A., Kalia, R. K., Vashishta, P., and Loong, C.-K., Oxidation dynamics of nanophase alumium clusters: a molecular dynamics study, Mat. Res. Soc. Symp. Proc. , submitted (1998).

30. Marshall, D. B., Morgan, P. E. D., Housley, R. M., and Cheung, J. T., High-temperature stability of the $\mathrm{Al}_{2} \mathrm{O}_{3}-\mathrm{LaPO}_{4}$ system, J. Am. Ceram. Soc. 81, 951 (1998).

31. Nipko, J. C., Loong, C.-K., Loewenhaupt, M., Braden, M., Reichardt, W., and Boatner, L. A., Lattice dynamics of xenotime: the phonon dispersion relations and density of states of $\mathrm{LuPO}_{4}$, Phys. Rev. B 56, 11584 (1997). 
Figure Captions:

Figure 1. The phase diagram of the $\mathrm{SiO}_{2}-\mathrm{Si}_{3} \mathrm{~N}_{4}-\mathrm{AIN}-\mathrm{Al}_{2} \mathrm{O}_{3}$ system, after Ref. 1 .

Figure 2. The observed generalized phonon density of states of vitreous silica at $10 \mathrm{~K}$.

Figure 3. The neutron (symbols) and MD (solid line) generalized phonon density of states of $\beta-\mathrm{Si}_{3} \mathrm{~N}_{4}$.

Figure 4. Measured (open circles) and calculated (lines) generalized phonon density of states for AIN. The solid line denotes the sum of the one-phonon and two-phonon DOS and the dashed line denotes the two-phonon contribution.

Figure 5. The calculated phonon dispersion curves of AlN along the major symmetry directions: $\Delta$ $[0,0, x], \Sigma[x, 0,0], T[x, x, 0]$. The right panel: the true phonon density of states of AIN.

Figure 6. The true phonon densities of states of AIN and GaN calculated from the rigid-ion model.

Figure 7. The neutron (symbols) and MD (solid line) generalized phonon density of states of $\alpha-\mathrm{Al}_{2} \mathrm{O}_{3}$.

Figure 8. The observed generalized phonon densities of states of $\mathrm{Si}_{6-z} \mathrm{Al}_{z} \mathrm{O}_{z} \mathrm{~N}_{8-z}$ for $\mathrm{z}=0,2,4,5$ and 6. 


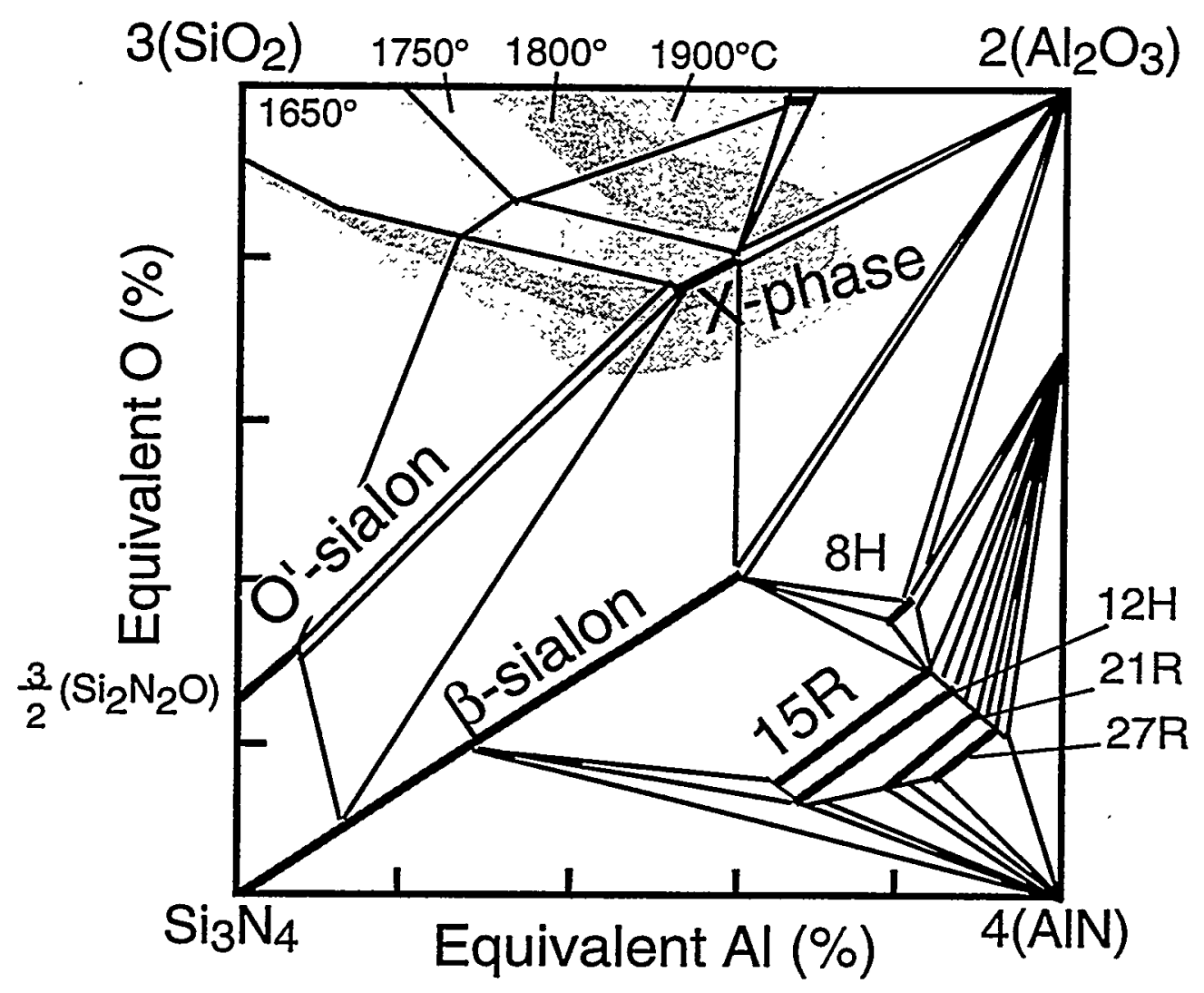

Fig. 1. Loong, "Phonon Densities of States and Thermal Properties of High Temperature Ceramics" 
Generalized PDOS (arb. units)

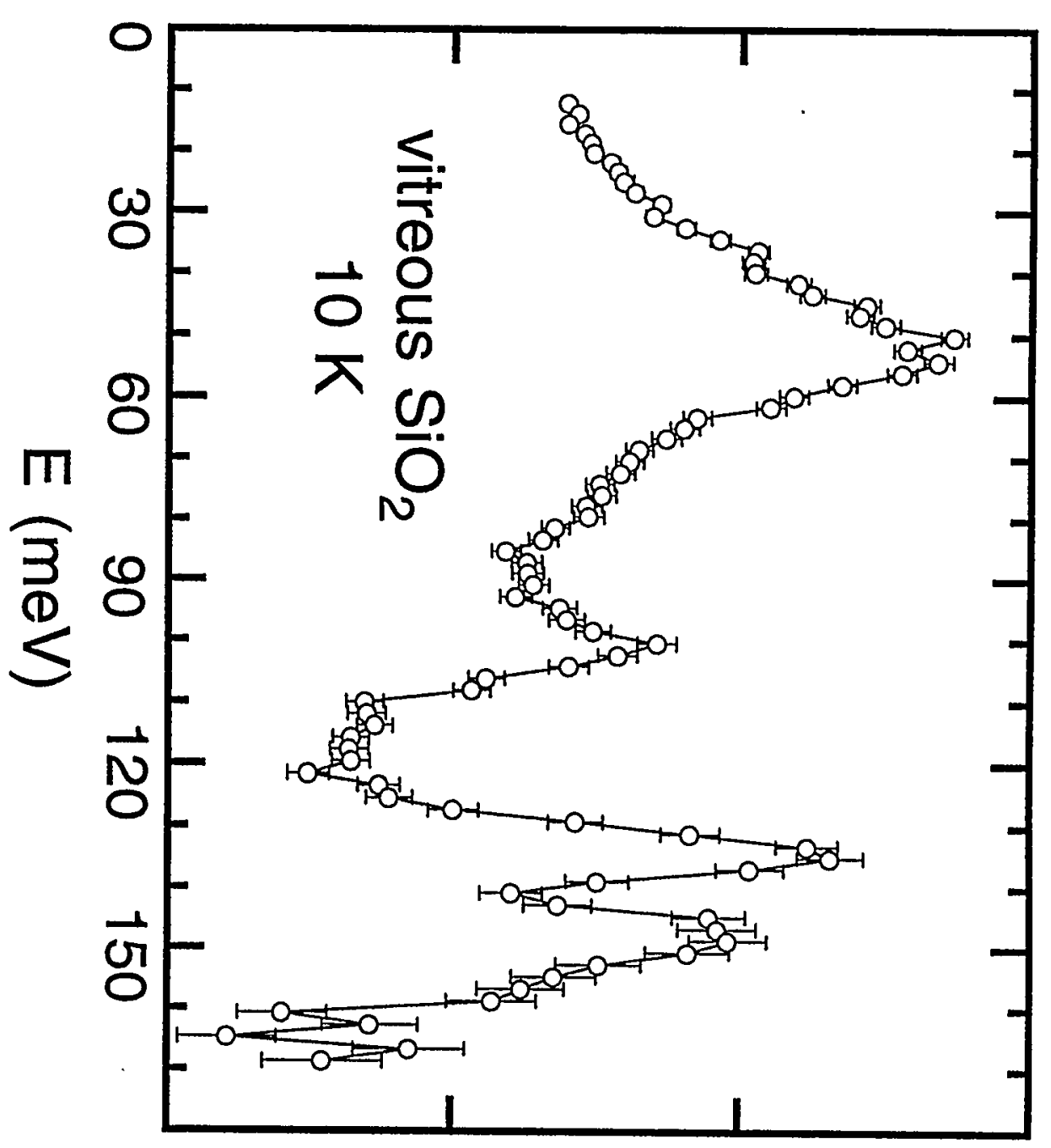




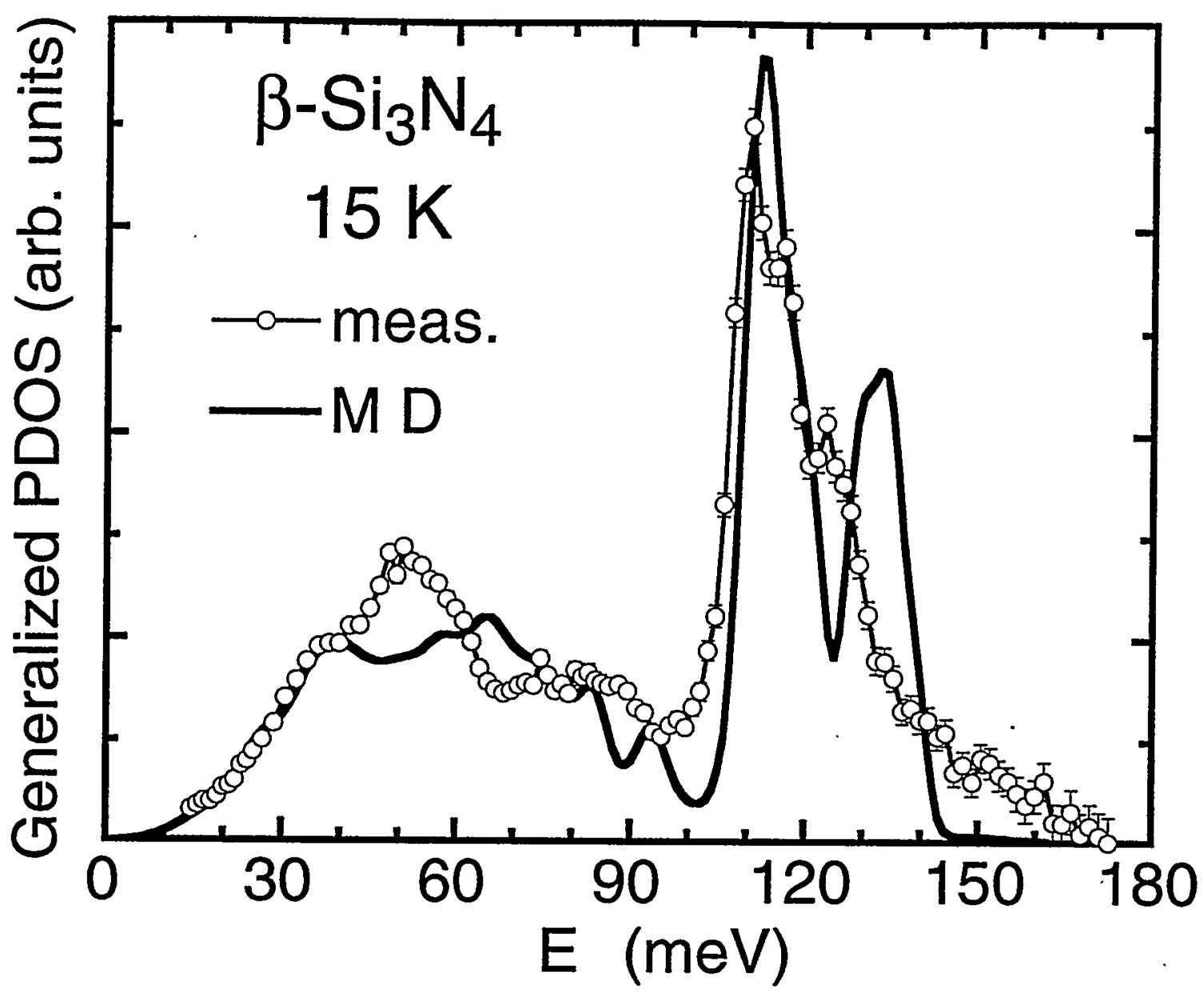

Fig. 3. Loong, "Phonon Densities of States and Thermal Properties of High Temperature Ceramics" 
Generalized PDOS (arb. units)

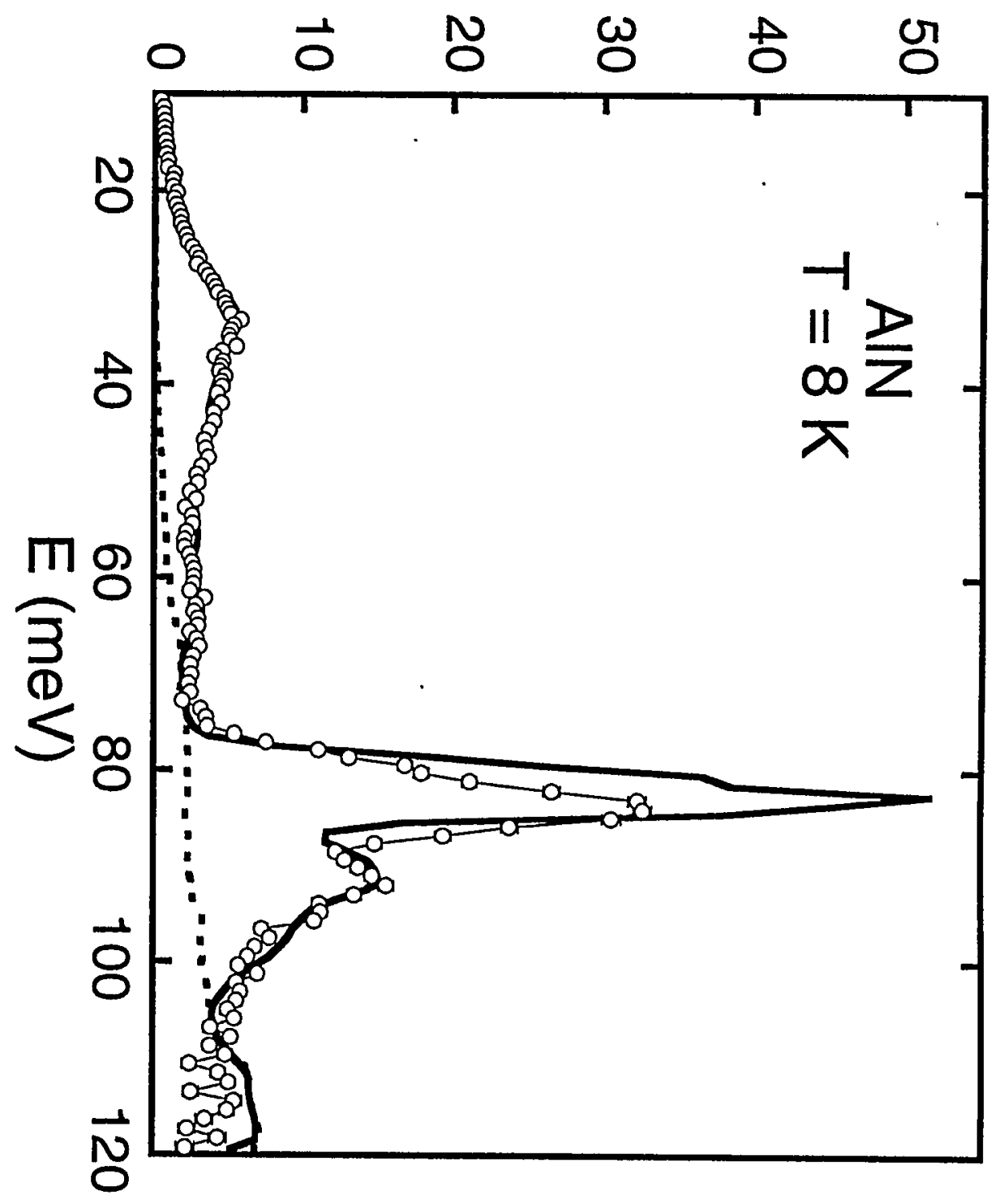




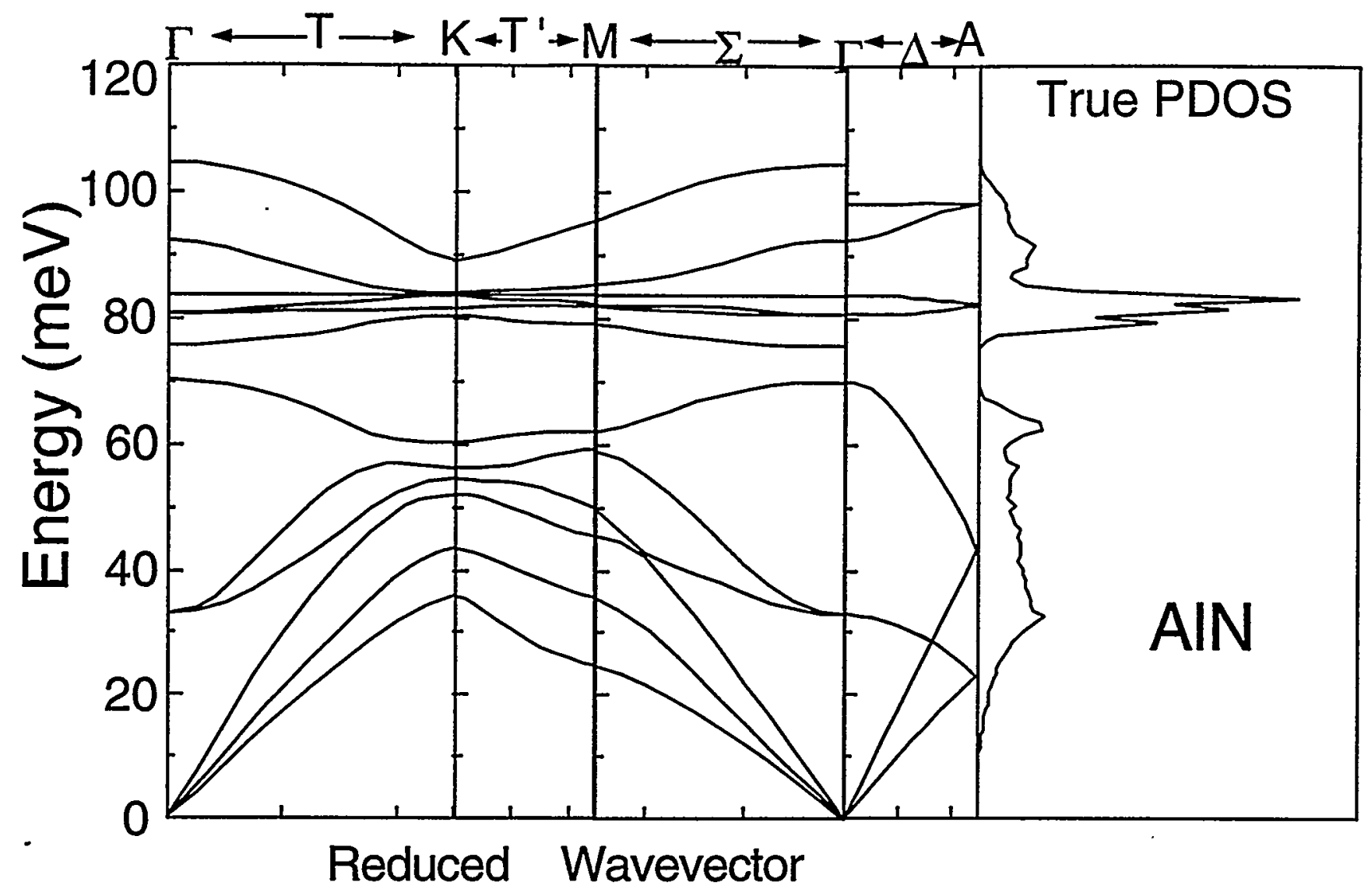

Fig. 5. Loong, "Phonon Densities of States and Thermal Properties of High Temperature Ceramics" 


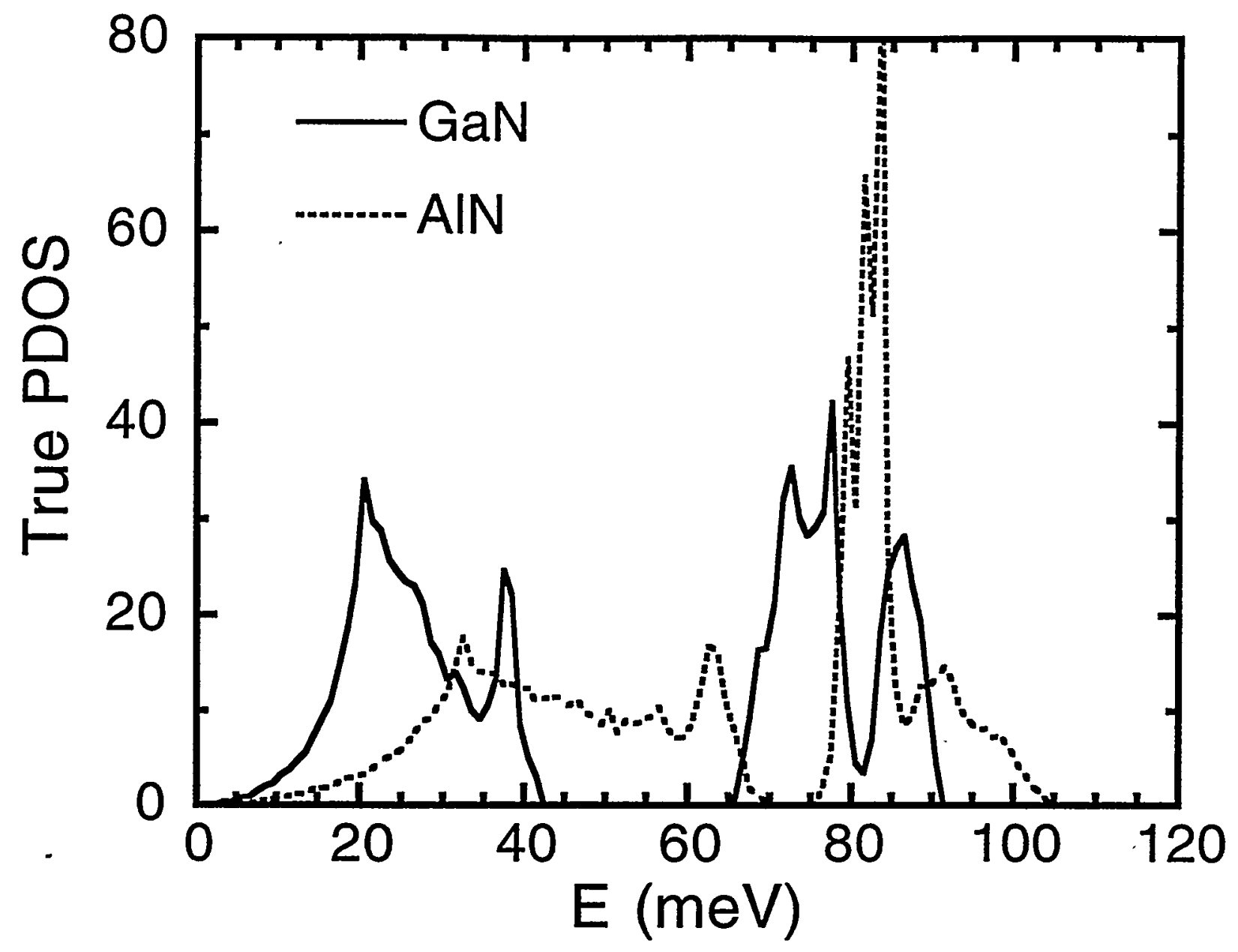

Fig. 6 Loong, "Phonon Densities of States and Thermal Properties of High Temperature Ceramics" 


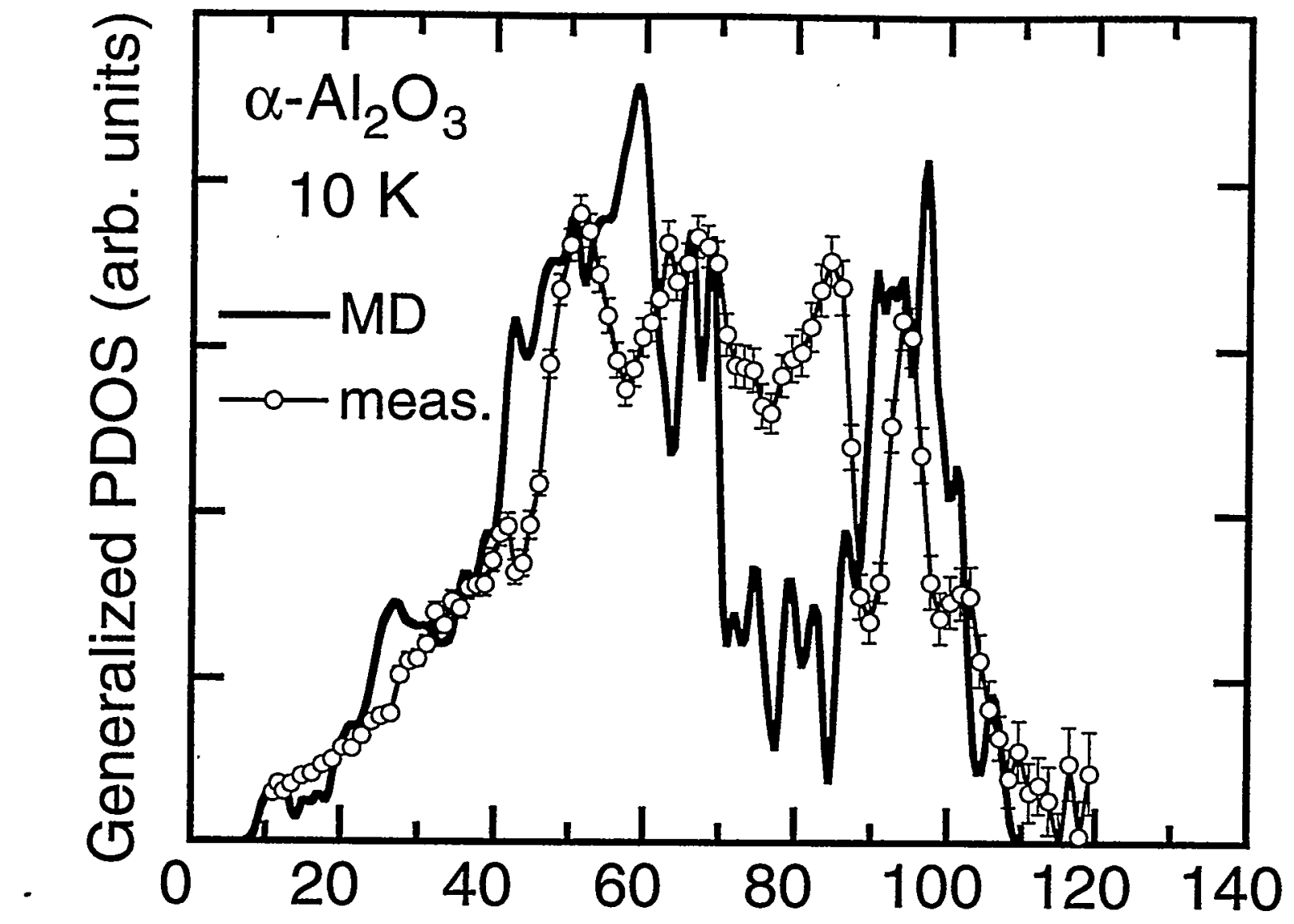

Fig. 7 Loong, "Phonon Densities of States and Thermal Properties of High Temperature Ceramics" 


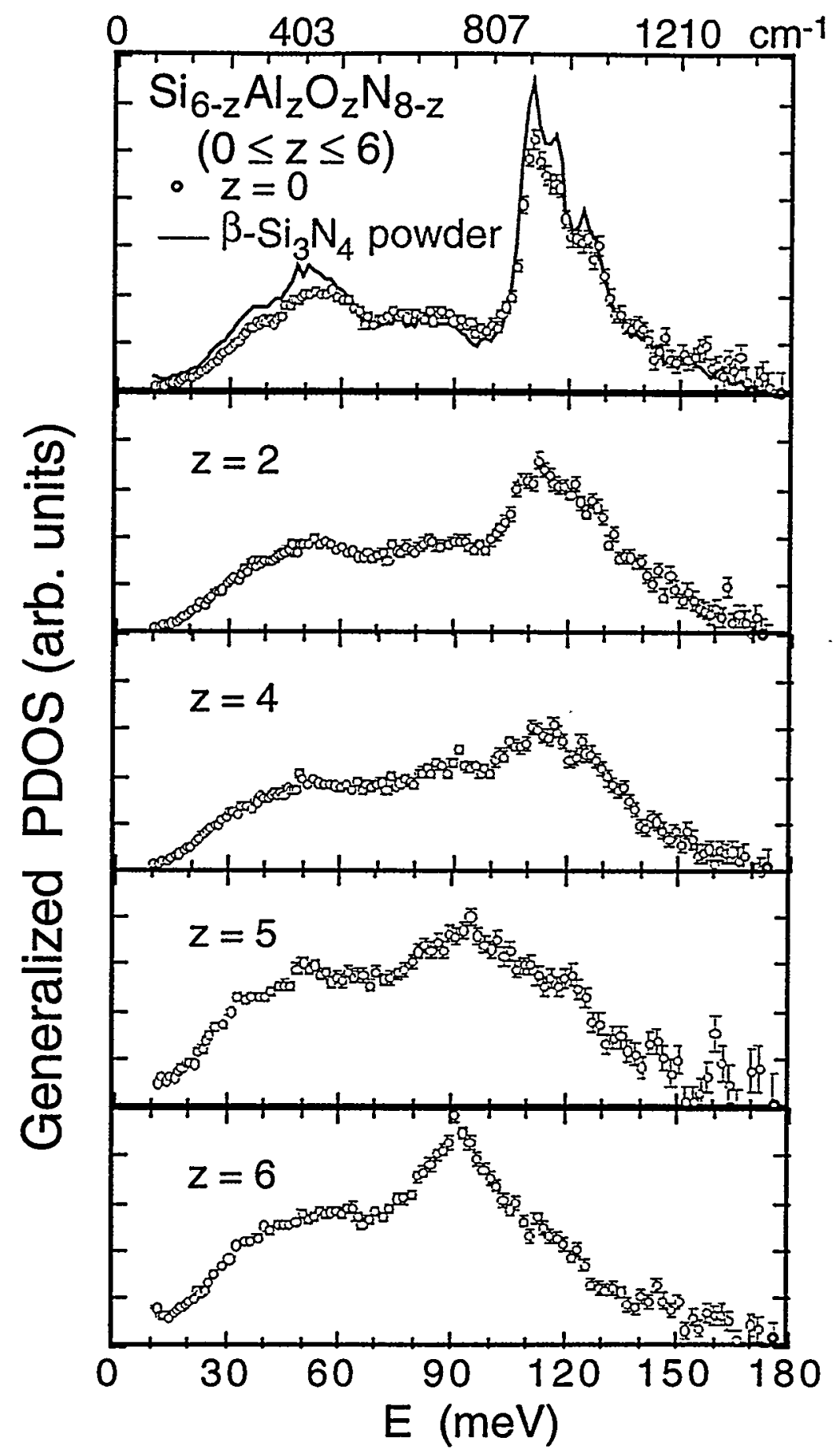

Fig. 8. Loong, "Phonon Densities of States and Thermal Properties of High Temperature Ceramics" 